weather. Wind from N.W. to S. and back again, from a light breeze to a moderate gale, barometer never rising higher than $29^{\circ} 90$ in., or falling below $29^{\circ} 66$ in.

The Cause of the Great Fire at St. John's.

A FEW days ago you inserted a letter calling attention to the large number of fatal accidents occurring every year caused by the upsetting of paraffin lamps, the great majority of which could easily be prevented if the use of automatic extinguishers were made compulsory.

Now we are startled by the report of the huge conflagration at St. John's, which, in addition to having caused terrible and widespread suffering, has resulted in the loss of a large amount of property, valued at many millions of dollars.

Amongst the principal sufferers by this great fire are some of the leading English insurance companies, and various estimates have been published of the amounts which they will lose by this great fire. The Policy Holder, an insurance journal, in its last issue, mentions the following figures :-

\begin{tabular}{|c|c|c|c|}
\hline & & \\
\hline Phœnix & & 120,000 to & 140,000 \\
\hline Royal , ... & $\cdots, \quad \cdots$ & 80,000 to & 100,000 \\
\hline Liverpool, Londo & and Globe & 50,000 to & 70,000 \\
\hline London and Lan & shire $\quad$. & 50,000 to & 60,000 \\
\hline Commercial Uni & & 40,000 to & 50,000 \\
\hline North British an & Mercantile & 50,000 to & 60,000 \\
\hline Northern $\quad \ldots$ & $\cdots$ & 40,000 to & 50,000 \\
\hline Manchester ... & $\ldots$ & 8,000 to & I 1,000 \\
\hline re $\ldots$ & $\ldots$ & 5,000 to & 7,000 \\
\hline orwich & $\ldots$ & 7,000 to & 10,000 \\
\hline
\end{tabular}

Also the "General," said to be $£ 30,000$, and the "Lion" for a comparatively large sum, making in the aggregate a loss for English insurance companies alone of over $£ 500$, o00 sterling.

The same journal explains how this great fire was brought about :-

"It is worthy of note that, like the Chicago fire, this con. flagration was caused by the upsetting of an oil lamp in a stable. Fire business was already this yeargoing badly enough, and there now seems little reason to doubt that to the companies as a whole 1892 will prove a disastrous year and a dead loss."

The Mayor of Manchester (Alderman Bosdin Leech), in presiding yesterday at a meeting of citizens called for the purpose of raising a fund in aid of the sufferers by this great catastrophe, stated-

"Since the fire of forty or fifty years ago many substantial public and private buildings had been erected, all of which have been destroyed. On one side, at any rate, a thriving town had been reduced to a heap of ashes, and about ro, ooo people had been rendered homeless, and damage had heen done to the exten of about 2,500,000 dollars. With such an event coming suddenly upon them, they could imagine how the people were prostrated. The heart of the people was completely crushed. A great many of the sufferers were of the poorest class, and they were almost powerless to help themselves. They were without food, except such as had been supplied to them through the kind ness of their neighbours ; they were without clothes, for all their clothes had been destroyed; and, unfortunately, the working people of the community had been almost entirely bereft of the tools and implements with which they were in the habit of earning their daily bread."

It is indeed very sad to think that this terrible calamity might have been avoided had the oil lamp which was the cause of all this mischief been fitted with a simple application of science in the shape of a simple automatic extinguisher.

July 20.

Humanity.

\section{THE WASHINGTON COLLECTION OF FOSSIL VERTEBRATES}

$W^{E}$ are pleased to learn from a transatlantic contemporary that the enormous collections of vertebrate remains, obtained under the superintendence of Prof. O. C. Marsh from the Tertiary and Secondary strata of the north-western United States, are about to be

No. I I 87 , vOL. 46$]$ transferred to the National Museum at Washington, where they will eventually be properly arranged, and exhibited to the public. For the last nine years, as we are informed, the United States Government has voted funds for the collection and preservation of these wonderful remains, descriptions of which have been from time to tirne presented to the scientific world with a wealth of illustration which cannot but render European palæontologists somewhat envious.

Hitherto the whole of this collection (together with Prof. Marsh's private collection) has been stored in the palæontological department of the unfinished Peabody Museum, at Yale College, New Haven, Conn.; where want of space has totally prohibited its proper exhibition. Indeed, those who have had the opportunity of inspecting this unrivalled series inform us that the specimens are so crowded together-the smaller ones in tier upon tier of trays, and the larger ones on the floors and in every available corner-that it has hitherto been quite impossible to form any adequate judgment as to the extent and importance of the collection. It is, however, satisfactory to learn that the whole series has been carefully labelled and registered, so that the locality and date of acquisition of every individual bone are fully recorded.

To prepare such an enormous collection for transit by rail is a work demanding both extreme care and a considerable amount of time; while the Museum space required for the exhibition of entire skeletons of the bulk of those of the Jurassic and Cretaceous Dinosaurs must be proportionately extensive. We are informed, indeed, that if the whole collection were transferred to Washington at the present time it would occupy fully one-half of the buildings of the National Museum. Accordingly, only a portion of it is to be immediately transported; while the remainder is to wait until Congress has provided suitable quarters for its reception. It is to be hoped that the moiety now to be transferred will include a representative selection from the entire series, so that palæontologists will have an opportunity of seeing more or less nearly entire skeletons, not only of the Dinosaurs and other huge Saurians of the Mesozoic, but likewise those of the equally wonderful Tertiary mammals. We may also venture to express the hope that the United States Government will before long see its way to enriching European Museums with some of their duplicate specimens, of which there must be a large number for disposal.

With a wise liberality, the Government of the United States appears to have made a regular business of the collection of these fossils, under the able direction of Prof. Marsh; this business being conducted much after the manner of any other mining enterprise. One of the favourite hunting-grounds is the region Jying between the "Rockies" and the Wasatch Mountains; and the accounts of the richness of some of these deposits in vertebrate remains is absolutely marvellous. Thus Prof. Marsh is reported to know of one small valley where bones of Mosasaurians are in such profusion that in passing through it he observed at one time no less than six entire skeletons of these monstrous reptiles, each averaging some 80 feet in length. At such a rate of dis. covery it is nowonder that Museum accommodation cannot be procured fast enough. The care taken to prevent other fossil-hunters from discovering the more productive localities affords rather amusing reading; but, under the circumstances, it is, perhaps, natural.

Whenever a likely-looking bone or skeleton is seen projecting from a rocky cliff, skilled workmen are at once set to work on its extraction; a single specimen sometimes leading to the discovery of a regular golgotha of remains. The wonderfully perfect condition of some of these fossils, and the rapidity with which the carcasses of their former owners must have been entombed in sand 
or mud, are brought prominently under notice by a recent reported discovery in Wyoming. This is said to be nothing less than the disentombment of an entire skeleton of that stupendous Dinosaur known as the Brontosaur, in which not only is every bone in place, but an actual mould of the surface of the eye, formed in the sand upon which the creature lay, has been preserved in the solid rock.

Prof. Marsh's restoration of the Brontosaur-a creature 60 feet in length, walking on all fours, with an enormously long neck and tail, a disproportionately small head, and the bony substance of its backbone reduced to a mere shell and a honeycombed interior-has been long before the world. Less known, however, is his later reconstruction of the skeleton of one of the gigantic horned Dinosaurs from the Laramie Cretaceous, which he calls Triceratops; the skull and pelvis of which were referred to in an earlier number of NATURE. In this restoration the Professor has certainly succeeded in producing a most marvellous animal, although, so far as we see, the figure appears to be true to nature. It will be remembered that one of the most remarkable features in the skull of Triceratops (which in some specimens was upwards of 12 feet in length) is the production of the hinder regi on into a huge fan-like shield. the use and purpose of which it was at first a little difficult to understand. This is, however, explained by the restored skeleton, where we see this shield overlapping and protecting the first six vertebræ of the neck; to which additional strength was imparted by the bony union of several of them. In the shortness of its neck and the enormous size of its skull, Triceratops presents a striking contrast to Brontosaurus. Like the latter, however, it habitually walked on all fours; while in correlation with its massive skull its forelimbs were relatively stouter than in any other Dinosaur. In this respect it differs widely from its near ally, Stegosaurus, which, at least occasionally, walked in a bird-like manner; and since Triceratops ${ }^{\circ}$ is evidently a more specialized creature than Stegosaums, the suggestion arises that the former has undergone a retrograde development from a bipedal to a quadrupedal mode of progression. No attempt has yet been made to represent the position on the skeleton of the dermal bony armour with which many parts of the body of Triceratops were protected during life; the precise position of the various spines, knobs, and plates, which have been found in assnciation with the bones, being largely a matter of conjecture. The size in life of the restored example would be approximately some 25 feet in length by Io in height ; but these dimensions must have been exceeded by other specimens.

By the completion (so far as anything connected with fossils can be said to be complete) of our knowledge of the skeleton of Triceratops, we are acquainted with the bony framework of all the chief types of Dinosaurian reptiles at present known. These may be classed as the Sauropodous type, as represented by Brontosaurus; the Theropodous type, as represented by Megalosaurus and its allies; and the Ornithopodous modification, represented on the one hand by Iguanodon, and on the other by Stegosaurus, Triceratops, \&c.

In the contemporary publication to which we have referred some interesting suggestions as to the probable habits of these Dinosaurs are put forth, although how far they will meet with acceptation remains to be seen. Thus it is suggested that the honeycombed vertebræ of the Brontosaurs and their allies were filled with warm air from the lungs (which assumes that these reptiles were warm-blooded), by which means their bodies were partly floated when they wandered out of their depth in the sea shallows, from whence they stretched their long necks to crop the seaweed near the shore. Again, the long hind legs of the Hadrosaur (an ally of our Iguanodon) are considered to have enabled their owner to wade far out to sea in search of seaweeds growing on the oceanพо. I I 87 , VOL. 46 ] floor; while the armoured kinds, like Stegosaurus and Triceratops, are considered to have been essentially terrestrial.

As we have indicated, the great bulk of the collection is composed of Secondary reptiles and Tertiary mammals; and from their large size it is these which form its most striking feature. We most not omit to state, however, that it also contains the Toothed Birds from the Cretaceous of Kansas (of which our English collections do not at present possess a single bone), as well as hosts of teeth of Mesozoic mammals, although we have no definite information as to what proportion of these are the property of the State, and what belong to Prof. Marsh. Then, again, scattered among the trays and drawers more especially devoted to the remains of mammals and reptiles is an extensive collection of fishremains from Cretaceous and Tertiary strata, and especially from the Green River Eocene shales of Wyoming, most of which we believe to be at present totally undescribed.

Space prevents us from saying more as to the extent of this marvellous collection-a collection which, with others from the same regions, has done more in ten years to revolutionize our classifications, and to give us a definite knowledge of many groups of animals previously known by battered fragments, than would have resulted from half a century's work upon European materials. We may, however, conclude by offering our hearty congratulations to the Governments of the United States and to Prof. Marsh, who have succeeded, by the liberality of the one and the untiring energy of the other, in amassing this magnificent collection, which is now, for the first time, in a fair way to be exhibited in a manner befitting its value and importance. Prof. Marsh's magnificently illustrated monographs on the Toothed Birds and the Dinocerata are splendid examples of how a collection like this ought to be made known to the scientific world at large ; and we trust ere long to be able to welcome his long-promised volumes on the Dinosaurs and the Brontotheres, which will render its riches yet better known.

R. LYDEKKER.

\section{DYNAMO-ELECTRIC MACHINERY.}

THIS is the first part of a treatise dealing with dynamo-electric machinery and its applications, and comprises the theory and practical construction of dynamos and motors, and an account of instruments and methods of electrical measurement. Such subjects as the fusion and welding of metals by electricity and the transmission of power are reserved for a second part, to be issued in the autumn of the present year.

The author begins with a chapter entitled "Generalities regarding Dynamos," in which he discusses the early rudimentary magneto-machines of Pixii and Clarke, and the multipolar machines of the same class invented by Stöhrer and Niaudet, gives a general explanation of the self-excitation and action of series of shunt and compound dynamos, and describes the various typical forms of armature used in constant and alternating-current machines. In this part there is room for little novelty of treatment; the author could only endeavour to be impartially historical and clearly descriptive, and give as complete and useful an account of the more important examples of dynamo machinery as his space would admit of. In this Signor Ferrini seems to have succeeded very well. He does not weary his readers with descriptions of mere antiquities, but supplies only such a brief account of earlier forms as is sufficient to enable the reader to trace the evolution of the modern constant-current dynamo, with its beautiful balance and inter-relation of

x “Recenti Progressi nelle Applicazioni deiì Elettricità di Rinaldo Ferrini." Parte Prima: Delle Dinamo. (Milano: Ulrico Hoepli, r 802 .) 